\title{
CONTINUOUS MONITORING OF INDUSTRIAL AIR EMISSIONS - PRECONDITION FOR BASELINE ASSESSMENT AND EFFECTIVE IMPLEMENTATION OF CLEANER PRODUCTION INDICATOR SYSTEM
}

\author{
BAKRESKA KORMUSHOSKA, N[atasa] \& KOCHOV, A[tanas]
}

\begin{abstract}
Continuous monitoring of air emissions is a precondition for establishing a baseline impact assessment and effective implementation of Cleaner Production indicator system related to air emissions. This paper is going to present the air monitoring system established in the Usje cement Plant. Usje cement Plant is a member of the TITAN Group, a multiregional producer of cement and an active part of the community. The plant is located in the south-eastern part of Skopje, the capitol of Republic of Macedonia. Following TITAN Policy on Environment, focused on minimizing the impact of business activity on the natural world, Usje cement Plant is the first company in the country that has established independent continuous air monitoring system.

Established air monitoring System, enables closely monitor the emissions on real time basis and take action accordingly. At the same time, it gives to the stakeholders regular, and updated information on our performance.
\end{abstract}

Keywords: Air Emission, Cleaner Production, Cement Industry, Continuous Monitoring

\section{INTRODUCTION}

The purpose of Cleaner Production is continuous application of a preventive environmental strategy incorporated into processes, products and services in order to increase efficiency and reduce hazards for people and the environment. This strategy includes the gradual assessment and adoption of the best available techniques for minimizing environmental pollution that are technically viable in accordance with the specific characteristics of each production process [9-11].

Continuous monitoring of air emissions is a precondition for establishing a baseline assessment and effective implementation of Cleaner Production indicator system $[12,13]$. This paper is going to present the air monitoring system established in the Usje cement Plant.

Usje cement Plant is a member of the TITAN Group, a multi-regional producer of cement and an active part of the community. Usje cement Plant started with production in the year 1955, and today employs about 350 people. The plant is located in the south-eastern part of Skopje, the capitol of Republic of Macedonia, in a district which in the recent years becomes combined industrial and residential area.

Following TITAN Policy on Environment, focused on minimizing the impact of business activity on the natural world, and on developing initiatives enhancing natural environment, Usje cement Plant is the first company in the country that has established independent continuous air monitoring system [8]. The company SICK from Germany is the producer of monitoring equipment and software used.

\section{AIR EMISSION MONITORING}

Cement manufacturing, in an overly simplistic view is a four-step process: 1) raw material acquisition, 2) preparation of natural and alternative raw materials for pyroprocessing, 3) transformation of the raw materials into portland cement compounds within a pyroprocess that is fueled by fossil and other fuels, and subsequently cooling the resulting clinker, and 4) grinding of the clinker into cement, and its handling, storage and shipment.

One of the main environmental issues associated with cement production are emissions to air [1]. In order to improve the environmental performances and to enable proper management of air emissions, in year 2007 Usje Cement Plant completed the setting of the independent system for air emissions monitoring, that comprises continuous monitoring of dust, oxides of nitrogen $\left(\mathrm{NO}_{\mathrm{X}}\right)$, and sulfur dioxide $\left(\mathrm{SO}_{2}\right)$. Parameters as flow, temperature and pressure of the exhausted gases are also continuously measured and are used in calculation of output data [14-18].

The terms 'dust' or 'particulate matter' include emissions of coarse dust, fine dust, soot, particles and aerosols. Traditionally, the emissions of dust, particularly from kiln stacks, have been one of the main environmental concerns in relation to cement manufacture. The main sources of dust emissions are the raw material preparation process (raw mills), grinding and drying units, the clinker burning process (kilns and clinker coolers), the fuel preparation and cement grinding unit (mills). Dust emissions from cement kilns have been reduced dramatically over the last two to three decades due to regular improvements in design and operation, including increased use of modern de-dusting equipment [14-18].

The clinker burning process is a high temperature process resulting in the formation of nitrogen oxides (NOx). Nitrogen oxides are formed during the combustion process either by a combination of fuel nitrogen with oxygen within the flame or by a combination of atmospheric nitrogen and oxygen in the combustion air [14-18]. $\mathrm{NO}$ and $\mathrm{NO}_{2}$ are the dominant nitrogen oxides in cement kiln exhaust gases [6,7].

SOx emissions are predominantly (99\%) in the form of sulfur dioxide $\left(\mathrm{SO}_{2}\right) . \mathrm{SO}_{2}$ emissions from cement plants depend on the total input of sulfur compounds and the type of process used, and is primarily determined by the content of the volatile sulfur in the raw materials and possibly by the fuels [5]. The production and potential 

this area (active measuring distance). Using the wave length - specific light absorption by the gas mixture on the active measuring path, the GM 31 Transceiver unit (TR unit) determines the concentration of the gas components present. The light from TR unit passes through the active measuring path and is reflected by a triple reflector at the end of the probe. The reflected light is then diverted by the lens - splitting mirror to the polychromator module. The optical grid splits the light into its spectral components and projects it on the receiver element, which comprises a highly sensitive diode row.

The optimized algorithms of the GM 31 evaluation electronics process the measurement signal from the receiver element, together with the associated parameters, using the Differential Optical Absorption Spectroscopy method.

\subsection{Dust monitoring equipment}

The exhaust gasses emitted from the raw meal preparation and clinker production process contain dust. The bag filters are used for reduction of dust in exhaust gases from kilns and the ESPs (electrostatic precipitators) are used for reduction of dust in exhaust gases from clinker coolers. The concentration of dust in the cleaned gasses is measured by OMD 41 - dust concentration monitor. These instruments are installed on the stacks of the two kilns, as well as on two clinker coolers. The measurement method is based upon the transmissionmeter principle.

The exhaust gasses from the cement mills and vertical mill for solid fuel, also contain dust. The bag filters are used for reduction of dust in the exhaust gasses. The concentration of dust in the cleaned gasses is measured by FW 100 - instruments for continuous measuring of dust concentration. These instruments are installed on three cement mills and on vertical mill for solid fuel.

\subsection{MEAC Software}

For graphic presentation and statistical processing of collected data, Usje cement Plant uses MEAC 2000 - PC software. MEAC 2000 is an Emission Data Evaluation System designed for evaluation of emission data and enables collection, assessment, long-term storage of data and integrated visualization of the data derived from the emissions as well as remote data transfer.

MEAC 2000 consisted of 14 Data Acquisition Units (DAU), one Emissions PC running Windows NT and comfortable software with windows interface. The DAU collect and process data and present it to the MEAC2000 Emissions PC. DAUs are data-receiving units equipped with microprocessors. Their functions are to create (flow) mean values per minute, intake the state signals and output of analog and state signals. Minute values and state changes are transmitted to the Emissions PC either via fibre optics or modem. The radio clock in the emissions PC synchronizes connected DAUs.

Using MEAC 2000, emissions data evaluation system, the minute (raw) values, interval average (raw) values as 30 minute averages, as well as trends for average interval, as corrected, normalized values, daily monthly and annual average values are collected ,calculated and can be printed. The System also presents limits for daily values and daily, monthly and annual classifications. The system enables a classification of the recorded and the daily values in compliance with TA Luft, 13th, 17th and 27th BlmSchV and the cement industry regulations. All data are stored on the emission PC hard drive.

\section{ANNUAL AIR EMISSIONS IN USJE}

According to Plant's IPPC Permit with adjustment plan, issued by Ministry of Environment and physical planning, the emission limit values for dust in exhausted gasses from kilns and cement mills is $50 \mathrm{mg} / \mathrm{Nm}^{3}$. Emission limit value for $\mathrm{SO} 2$ from kilns is $400 \mathrm{mg} / \mathrm{Nm}^{3}$ and for NOx expressed as NO2 is $1300 \mathrm{mg} / \mathrm{Nm}^{3}$.

Following figures presents the annual average values of emissions and respective emission limit values.

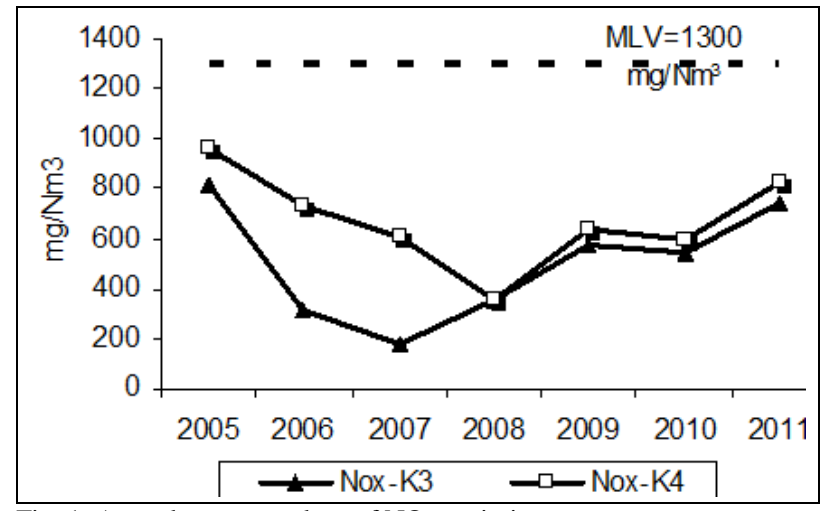

Fig. 1. Annual average values of NOx emissions

As it shown on the Figure, the overall NOx emissions are within the limits set by the local and EU legislation. This is the result of the continuous and systematic efforts to ensure the optimal performance of the pyroprocess units [2-4].

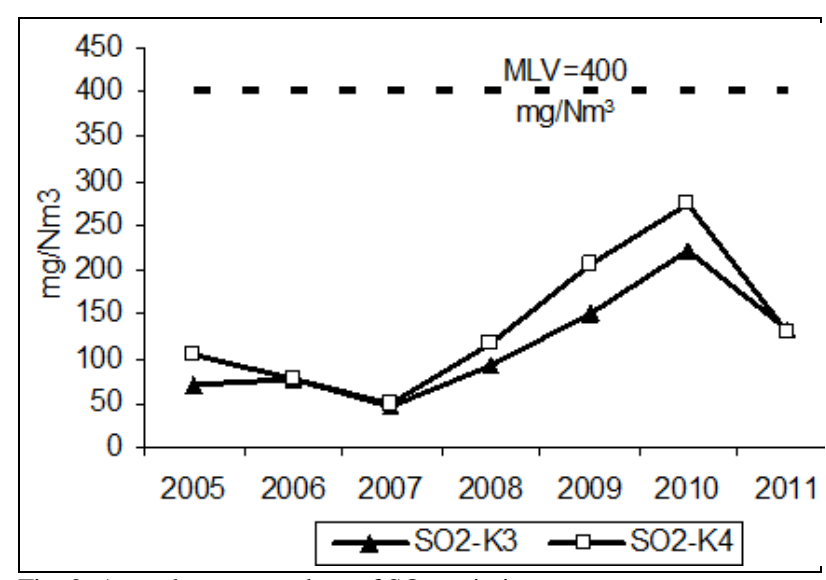

Fig. 2. Annual average values of $\mathrm{SO}_{2}$ emissions

USJE's SOx emissions are substantially below the limits (MLV) set by the applicable local and EU regulations. The presence of sulfur (S) in raw materials is the primary cause of SOx emissions. VDZ study prepared in the summer of 2010 proved that increased SO2 emissions in the period year 2008-2001 belong directly to the elevated sulfur in the marl raw material. Because of those findings, in year 2011, Usje changed marl exploration field, choosing one with less sulfur 
content, that led to evident reduction of $\mathrm{SO} 2$ emissions [2-4].

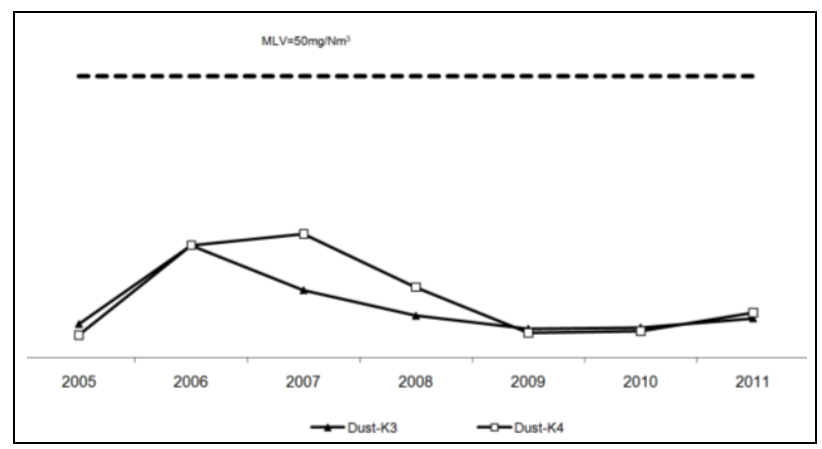

Fig. 3. Annual average values of dust emissions

Proper de-dusting system in the plant and installed bag filters enable dust emissions to be many times below the limits (MLV) set by the environmental terms and conditions of both local and EU legal requirements [2-4].

\section{CONCLUSION}

The process of cement production influences the environment. Cementarnica USJE operations are heavily dependent on the use of natural resources. We are aware of our impact on nature and that is the reason why the environmental care is our immense priority in all aspects of our conduct. For this reason, we are committed to actions that reduce our operational impact on the environment.

Above described monitoring System enables the Company to closely monitor the emissions on real time basis and take action accordingly. At the same time, it gives to the stakeholders regular, updated information on our performance.

Independent continuous monitoring of air emissions supports Usje's Sustainability reporting which is the practice of measuring, disclosing and being accountable to internal and external stakeholders for organizational performance towards the goal of sustainable development, including economic, environmental and social impact.

\section{REFERENCES}

[1] Manual of Pollution Prevention in the Cement Industry, (2008) Regional Activity Centre for Cleaner Production (CP/RAC)

[2] Stacker and reclaimer systems, (2005) FLSmith. Materials Handling

[3] Hendrik G. van Oss and Amy C. Padovani (2003), Cement Manufacture and the Environment

[4] Reference Document on Best Available Techniques in the Cement and Lime Manufacturing Industries (2001), Integrated Pollution Prevention and Control (IPPC). [BREF, 2001]

[5] Miller, F. M., Sulfuric Acid Mist - Potential for Emissions in Cement Manufacture: An Opinion, R\&D Serial No. 2509, Portland Cement Association, Skokie, Illinois, USA, 2001

[6] Miller, J. A., and Bowman, C.T., (1989) Mechanism and Modeling of Nitrogen Chemistry in Combustion, Progress in Energy and Combustion. Science, Volume 1

[7] Penta Engineering Corporation, (1999), Report on NOx Formation and Variability in Portland Cement Kiln Systems, Potential Control Techniques, and Their Feasibility and Cost Effectiveness, R\&D Serial No. 2227, Portland Cement Association, Skokie, Illinois, USA
[8] Cement Plant Usje, (2010), Corporate Social Responsibility and Sustainability Report, Skopje

[9] Enterprise-Level Indicators for Resource Productivity and Pollution Intensity, A Primer for Small and Medium-Sized Enterprises (2010) United Nation Development Organization, Vienna

[10] Baas L. (2006). Cleaner production systems in the context of needed partners and policies at the micro, meso and macro level UNIDO Cleaner Production Expert Group Meeting. Baden, Austria, 29-31 October 2006

[11] Baas L. (2005). Cleaner Production and Industrial Ecology, Dynamic Aspects of the Introduction and Dissemination of New Concepts in Industrial Practice. Erasmus University, The Netherlands

[12] Clark G. (2007). Evolution of the global sustainable consumption and production policy and the United Nations Environmental Programmes' (UNEP) supporting activities. Journal of Cleaner production, Volume 15, Number 6

[13] Greer, W. L. (2003), Interactions Among Gaseous Pollutants from Cement Manufacture and Their Control Technologies, R\&D Serial No. 2728, Portland Cement Association, Skokie, Illinois, USA

[14] Bogue, R. H., (1955) The Chemistry of Portland Cement, Reinhold Publishing Corp., New York, NY, USA

[15] Duda,W.H.,(1985) Cement Data Book, Bauverlag GmbH, Weisbaden and Berlin, Germany

[16] Labalm, O., Kohlhaas, B., (1983) Cement Engineers Handbook, Bauverlag GmbH,Wiesbaden and Berlin, Germany

[17] Peray, K. E., (1979) Cement Manufacturer's Handbook, Chemical Publishing Co., New York, NY, USA

[18] Peray, K. E., (1986) The Rotary Cement Kiln, Chemical Publishing Co., New York, NY, USA 